\title{
Waksman, V. (2016). El laberinto de la libertad: política, educación y filosofía en la obra de Rousseau. Ciudad Autónoma de Buenos Aires: Fondo de Cultura Económica
}

\author{
Ernesto García
}

Universidad Nacional de La Plata, Argentina | ernestogarcia dx@yahoo.com.ar

La principal hipótesis que sostiene Vera Waksman en el libro es que en la obra y la vida de Rousseau es posible identificar un concepto que puede ser pensado como un hilo conductor de sus reflexiones políticas, educativas y filosóficas, la noción de amor de sí mismo; y que al mismo tiempo existe en el autor una inquietud permanente que constituye el impulso para sus esfuerzos teóricos, la libertad.

Para llevar adelante este propósito, la autora considera el devenir de la propia noción de amor de sí mismo en la obra de Rousseau y la tensión a la que la noción está sujeta debido tanto a la posibilidad de convertirse en amor propio concentrado como de propiciar el desarrollo de un amor propio expansivo de pasiones amables y virtuosas hacia el resto de los seres humanos. La expansión o contracción del amor de sí mismo no es algo predeterminado, sino que en la definición de lo que suceda con esta pasión tienen un lugar especial las figuras de los personajes excepcionales, estudiados profundamente por la autora. La hipótesis de Vera Waksman se refiere no sólo a la obra de Rousseau, sino también a su vida. En este punto el estudio de la noción de amor de sí y de la libertad conduce a un análisis acerca de Rousseau como filósofo y su relación con Sócrates, así como del rol que el filósofo y la filosofía tienen en la propuesta del autor ginebrino.

El laberinto de la libertad consta de cuatro partes, cada una de ellas conformada por dos capítulos. 
Las partes están organizadas temáticamente en función de los problemas de la obra de Rousseau que se abordan en cada una de ellas: la antropología, la educación, la política y la filosofía.

En la primera parte la autora se encarga de analizar la antropología de Rousseau, entendiéndola como una base desde la cual el pensador parte para luego establecer las características de su propuesta educativa y política. Un aspecto que aparece prontamente en el libro es la distinción entre dos niveles de argumentación en Rousseau: los hechos y el derecho o los principios. Distinción que acompaña también a su planteo político y que genera ciertas tensiones de difícil conciliación.

En lo referente a la noción de estado de naturaleza, Waksman se distancia de quienes interpretan que Rousseau postula un principio "bueno”, el amor de sí, y un principio “malo”, el amor propio. El amor de sí que es acallado por el desarrollo de la razón no es anulado sino que muta en amor propio. Como la perfectibilidad y la totalidad de las facultades en general, el amor propio no es malo en sí mismo, sino que depende de las instituciones y de las relaciones que establezca con su entorno, relaciones que pueden ser de concentración o de expansión.

En lo referente al desarrollo de la sociedad humana y al devenir de la historia, Waksman sostiene que en las tesis de Rousseau existe una libertad originaria que se desvía, pero las causas de este desvío de la libertad no están en la naturaleza humana. Esta posición tiene importantes consecuencias políticas ya que si el proceso de desarrollo de la historia sucede a partir de una serie de acontecimientos azarosos -la aparición de la familia primero y de la agricultura y la siderurgia luego- entonces, por ejemplo, la propiedad de la tierra no resulta inherente a la naturaleza sino que es una contingencia más. Por tanto, la estructuración del orden político y social, junto a la constitución particular de los ciudadanos que lo habitan es modificable. Rousseau sostiene que del estado de competencia y desigualdad se sale mediante el pacto del rico, en el cual éste no considera el interés común, sino que generaliza el suyo propio cristalizando las injusticias del estado de naturaleza. En la consideración del pacto del rico, Waksman se diferencia de los autores que lo califican como inicuo por “abusivo”, así como también de quienes postulan una diferencia entre el pacto del rico y el pacto del contrato social. La autora sostiene que el pacto del rico es de obligación y sumisión y, aunque injusto por no contemplar el interés común, es válido dado que todos reconocen la necesidad de pactar.

En la segunda parte del libro, Vera Waksman analiza la propuesta que realiza el filósofo sobre cómo deben ser los hombres y la forma que debe adoptar su educación para lograr llegar al amor propio expandido necesario para constituir la voluntad general. Para Rousseau los hombres deben conocer sus verdaderas relaciones con las cosas y con los demás hombres. El centro desde el cual cada hombre establece sus relaciones es lo que el autor denomina estado de hombre, que refiere a la ausencia de rangos sociales y la igualdad de los hombres entre sí. Este estado no se identifica ni con el de naturaleza ni con el social, es un estadío previo necesario para formar parte del Estado político: se necesita ser hombre antes de poder ser ciudadano.

La educación de Emilio será doméstica, y esto la diferenciará de una educación como política de un Estado. Esta última debe inculcar el amor a la patria, la virtud y la libertad, con el objetivo de formar ciudadanos. La educación de Emilio, en cambio, busca formar al individuo para que comprenda su propio interés y pueda expandir el amor de sí mismo para ser capaz de integrar la voluntad general. Emilio recibirá una educación negativa, llamada así porque primordialmente 
estará enfocada a proteger al niño del vicio y el error. Las lecciones del tutor no provienen de sus palabras, sino de las experiencias que el propio niño irá viviendo. El tutor, como personaje excepcional, debe ordenar la materialidad para dar lugar a las experiencias y para ello debe contar con una capacidad de previsión. La educación negativa está basada en el orden necesario de las cosas y no en el orden arbitrario de los hombres, no busca anticipar el desarrollo del niño sino que atiende al tiempo presente. Luego en la adolescencia tendrá lugar para Emilio la educación de las pasiones, en donde resulta esencial el desarrollo de la imaginación como facultad que permitirá convertir a la piedad natural en un sentimiento moral, sentando así la posibilidad de expandir el amor de sí hacia otros. Waksman considera que en la propuesta educativa rousseauniana lo más importante es la perspectiva del espectador o, podríamos decir, del educando: las relaciones de hombre y sus pasiones, tanto a nivel individual como con la especie, deben ser sentidas y no tan sólo conocidas, y esta capacidad de sentirlas se desarrolla desde un lugar específico que se ha ido constituyendo desde el principio de la educación de Emilio.

Seguidamente, la autora considera que la religión tiene en Rousseau una necesidad y una utilidad que no puede reducirse a una mera instrumentalización de la creencia. En el caso de la religión civil, Waksman se distancia de aquellos que, como Postigliola (1972), ven en ésta un instrumento al servicio de la política; como así también de aquellos que, como Pierre-Maurice Masson (1911) consideran que el objetivo de Rousseau es el teísmo. Según la autora, en la propuesta del filósofo la política decide sobre la religión. Debe dar a ésta un contenido y una función. La religión es considerada un elemento de unión social y provee la garantía de un sentido a las acciones, una cierta teleología, que no es objeto de conocimiento ni puede afirmarse verdadera, pero favorece la expansión del amor de sí. En el planteo rousseauniano, lo religión es necesaria como resorte afectivo y pasional que sostenga la abstracción especulativa de la virtud y el amor al orden. Al mismo tiempo, Rousseau realiza una profunda crítica a la institución religiosa que pretende generar una obediencia irreflexiva por mediación de la revelación, así como también rechaza todo lo que parece contrario a la razón como los milagros o las profecías. La religión civil, por su parte, no es un fundamento del orden político, sino que ella misma es producto de la voluntad general y su función es tanto neutralizar los modos nocivos de la religión como definir una base mínima de creencias que es necesario defender para la subsistencia del cuerpo político.

La tercera parte del libro es en la que se estudia la propuesta política de Rousseau. Este apartado está dividido en dos capítulos, que representan dos momentos en la argumentación política de Rousseau: el instante del establecimiento de la libertad, y la duración, que corresponde a su realización. En lo referente al instante y a las condiciones de la libertad, Waksman se centra en la concepción de la voluntad general, incorporándose a esta discusión desde una perspectiva que sostiene que la voluntad general no puede pensarse en términos de la especie, sino del cuerpo político en el Estado; ya que sólo de esa manera puede constituirse en regla de lo justo y lo injusto. En lo que refiere a la duración de la libertad, la autora presta especial atención al personaje del legislador extraordinario, una figura que en sí misma expresa diversas tensiones y problemas. El legislador no sólo debe dar leyes sino también transformar la naturaleza humana. Lo extraordinario de este personaje está dado porque posee un saber no disponible para la mayoría y una capacidad de advertir el tiempo oportuno para la acción política. Sin embargo, su presencia es contingente y su autoridad no deriva de la voluntad general, puesto que ésta aún no existe. El amor de sí es el 
fundamento último de la voluntad general y es el que garantiza que cuando ella sea la regla no habrá contradicciones entre el interés de cada uno y el interés general. Es el amor de sí el fundamento del origen y la conservación del cuerpo político y por eso su cuidado, desarrollo y expansión ocupan un lugar central en la obra de Rousseau.

En la cuarta y última parte del libro la autora se encarga de analizar el rol del filósofo y la filosofía en Rousseau. La filosofía brinda la posibilidad de librarse de la servidumbre mediante el cultivo de sí. En esta parte encontramos un estudio de la identificación e inversión que realiza Rousseau con la figura de Sócrates, como alegoría del lugar del filósofo en el pensamiento del ginebrino. El filósofo es quién puede volver a la unidad perdida del hombre de naturaleza, tiene un rol de previsión y advertencia que implica riesgos. La filosofía, como la política, requiere un ámbito en el que sea posible reconocer al otro como adversario. Sin este ámbito, el conflicto implica la eliminación del contrincante y el filósofo debe volverse sobre sí mismo para evitarla. Rousseau está llevando a la teoría la propia experiencia de su vida, con el complot que sufrió en su contra. Waksman sostiene que el filósofo vuelto sobre sí buscará la sabiduría, entendida como una identificación con la naturaleza: el lugar del filósofo son los márgenes. El círculo se cierra y el filósofo recupera, luego del recorrido, el sentimiento de existencia que tenía el hombre salvaje, ya no necesita ni depende de otro para ser lo que es.

Waksman sostiene en sus conclusiones que continúa presente una tensión referida a la relación entre el principio inmanente del amor de sí -que es el que garantiza que la naturaleza humana sea transformable- y la intervención de personajes extraordinarios que remiten a un orden superior. Los personajes extraordinarios en Rousseau son, según la autora, los encargados de realizar los saltos que permiten el pasaje desde los principios a los hechos. Una de las conclusiones desafiantes de la autora es que el carácter único de los personajes excepcionales se basa no sólo en su saber, sino en una capacidad particular de acción. En el caso del legislador, una condición esencial para el desempeño de su tarea es que tenga poder, no es concebible su función sin poder, y justamente esto puede llevar a una tensión o contradicción con la idea de soberanía de la voluntad general.

La autora también sostiene la dualidad de la legislación: no es nada porque no ha sido establecida por la voluntad general, pero está autorizada desde la ley de naturaleza. La nada da cuenta de una instancia vacía, de la necesidad de apoyar la política en una instancia metapolítica desde la cual se fundamente el orden político. La política es autónoma, y sólo se funda en la voluntad de los hombres reunidos, no en otro ámbito. Finalmente, la autora retoma la preocupación por la libertad sosteniendo que, si bien Rousseau postula la soberanía popular, la igualdad no es previa al establecimiento de la sociedad política. Sólo la superioridad excepcional funda la igualdad y sólo desde esa dependencia se accede a la libertad.

La propuesta de pensar la noción de amor de sí como hilo conductor que anima la obra y la vida de Rousseau resulta novedosa y nos permite acercarnos a la obra del filósofo desde una perspectiva que la aborda en tanto totalidad. La copiosa cantidad de autores y posiciones con las que Vera Waksman dialoga a lo largo del texto también da cuenta de la profundidad del trabajo y la seriedad de la propuesta.

Consideramos importante mencionar que producto del enfoque adoptado por la autora, las tensiones entre inmanencia y trascendencia en la obra de Rousseau son expresadas con claridad. La 
inmanencia del campo político como esfera autónoma está dada por el hecho de que el orden político es convencional y su origen no se encuentra en Dios sino en un pacto entre los hombres que tiene su base en el amor de sí pero que se realiza por voluntad de los hombres. Sin embargo, al mismo tiempo que se plantea lo anterior, el lugar de los personajes excepcionales -el tutor y el legislador- ocupan en el planteo de Rousseau es el de ser articuladores de dos planos diferentes: los hechos con los principios y su particularidad es que remiten siempre a un absoluto que no está al alcance de cualquier hombre, lo cual los sitúa en un plano trascendente. La política entonces parece fundarse sólo en la voluntad de los hombres, sin requerir ningún absoluto divino o religioso que la justifique, pero al mismo tiempo la implementación efectiva de la sociedad política en la que pueda realizarse la libertad requiere la presencia de personajes excepcionales. Estas tensiones presentes en el pensamiento de Rousseau pueden remitir a distintas problemáticas de la vida política como el lugar del mito y los liderazgos políticos en la conformación de identidades colectivas, la relación entre participación y representación, o las tensiones asociadas a la configuración del sujeto pueblo, entre otras cuestiones que siguen abiertas para el debate y la producción teórica.

Para aquellos interesados en la educación y su relación con la filosofía política, esta obra constituye un material necesario no sólo por el recorrido que realiza por las tesis esenciales del pensamiento de Rousseau y las objeciones que debieron afrontar por parte de sus contemporáneos, sino también por los debates que la autora sostiene con comentadores y especialistas contemporáneos en el tema. La reconstrucción de la noción de educación negativa en vinculación con la necesidad de formar al ciudadano permite recuperar las relaciones entre la educación y la vida política. Este reencuentro entre educación, vida y política, que en parte es un entrecruzamiento producido y motivado por la figura del tutor/educador y el legislador/político, constituye un interesante aporte para tener presente en debates contemporáneos sobre las formas en las que la educación puede contribuir a mejorar nuestra vida en común junto a otros. Las obras clásicas y sus autores nos siguen interpelando a pesar del tiempo que ha pasado desde su aparición, y ese es el caso de un pensador como el estudiado por Vera Waksman, quién con sistematicidad y profundidad nos ofrece en este libro una lectura novedosa de la obra y la vida de Jean Jacques Rousseau.

\section{Bibliografía}

Masson, P. M. (1911). Rousseau contre Helvétius. Revue Littéraire de la France, t. xviii, 103-124

Postigliola, A. (1972). De Malebranche a Rousseau: les apories de la volonté générale et la revanche du 'raisonneur violent'. Annales Jean-Jacques Rousseau, (39), 123-138

Waksman, V. (2016). El laberinto de la libertad: política, educación y filosofía en la obra de Rousseau. Ciudad Autónoma de Buenos Aires: Fondo de Cultura Económica. 